\title{
A Review of Issues Concerning the Support for Fathers During Pregnancy: Research Trends in Japan
}

\author{
Izumi Ueda ${ }^{1}$, Asako Aoki ${ }^{1}$, Michiyo Hirano ${ }^{2}$, Naomi Okada ${ }^{1} \&$ Kazuko Saeki ${ }^{3}$ \\ ${ }^{1}$ School of Health Sciences, Sapporo Medical University, Sapporo, Japan \\ ${ }^{2}$ Faculty of Health Sciences, Hokkaido University, Sapporo, Japan \\ ${ }^{3}$ Faculty of Nursing, Toyama Prefectural University, Toyama, Japan \\ Correspondence: Izumi Ueda, Department of Nursing, School of Health Sciences, Sapporo Medical University, \\ South1 West 17, Chuo-ku, Sapporo, 060-8556 Japan. Tel: 81-11-611-2111 Ext 28620.
}

Received: October 22, 2021

Accepted: November 10, 2021

Online Published: November 26, 2021

doi:10.20849/ijsn.v6i4.938

URL: https://doi.org/10.20849/ijsn.v6i4.938

\begin{abstract}
Objective: To identify future issues in the development and implementation of support programs for fathers with the aim of preventing child abuse, we reviewed the domestic literature to determine the characteristics of support for fathers during pregnancy and identify research trends.

Methods: The domestic literature was searched on January 31, 2021, using the Central Journal of Medicine ver. 5.0. The search yielded 110 original articles and nursing literature using the keywords "pregnancy \& father" and "pregnancy \& husband," wherein 100 articles with abstracts were found, excluding conference proceedings. The abstracts were then checked, and finally, 27 were included in this analysis.

Results: In the articles collected, the following themes were extracted: "satisfaction from the experience of child-rearing skills from pregnancy," "relationship between marital intimacy and relationship to mother and child from pregnancy," "role adjustment between work and home from pregnancy," and "vague imagination and anxiety from pregnancy."

Conclusion: During pregnancy, the deepening of the relationship between the mother and father, who is still adjusting to become a father, can affect the quality of the relationship between the mother and the child. Thus, the challenge is to develop support programs that will further strengthen the relationship between the husband and wife.
\end{abstract}

Keywords: period of pregnancy, father, literature review

\section{Introduction}

The number of child abuse cases received by child guidance centers in Japan has seen a steady increase annually, with child abuse becoming a social problem in the country. A report by the Social Security Council as regards deaths due to child abuse has revealed an overview of the circumstances of death in all cases. According to the aforementioned report, $49.1 \%$ of deaths due to child abuse were children aged 0 years old, of which 0 -month-olds accounted for the highest percentage at 39.3\% (Syakaihosyousingikai, 2021). From the viewpoint of abuse prevention, infancy is a critical period with a particularly high risk. To prevent abuse, it is highly necessary to support parents from the time of pregnancy.

In Japan, each municipality formulates a maternal and child health plan through maternal and child health measures and systematically promotes a series of services throughout the process of pregnancy, childbirth, and child-rearing. As part of these services, interviews at the time of issuance of the Maternal and Child Health Handbook, home visits for newborns and expectant mothers, and infant health checkups are conducted by public health nurses for a long time (Ministry of Health Labor and Welfare, 2021). However, there seem to be limited opportunities to support fathers during pregnancy, such as parent-teacher classes (Adachi, 2020). Because the classes are voluntary, fathers are often left to their own devices. In addition, these classes often targeted to support mothers in raising their children and acquire skills, such as fathers' participation in childcare, learning newborn care, and simulating pregnancy, and only a few classes have abuse prevention as their purpose (Satou, 2006). Henceforth, providing support to fathers will be significant from the perspective of early prevention of 
abuse.

In Japan, research in the perinatal period from the perspective of child abuse prevention has focused on support programs for mothers and cooperation with related institutions (Kojima et al., 2014; Nakayama, 2016). There are only a few studies examining support given to fathers during pregnancy, utilizing parent-teacher classes (Watanabe et al., 2019) and practical reports of parent-learning support programs by local governments and NPOs. These programs, however, do not focus on child abuse prevention, and these mostly focused on knowledge about child-rearing and learning as children grow. One of the challenges is that parents need to learn social rules and discipline before learning child-rearing knowledge, and it is pointed out that it is significant to provide support that will encourage parents' own fundamental growth as a person (Nonoyama, 2010). Parenting education during pregnancy in the United States was for a long time targeted at mothers, but since around the 1970s, various efforts have been made to incorporate fathers in it. As research on transition to parenthood progressed, it has become widely recognized that preventive intervention is necessary for all parents, and preventive parent education and support from the period of pregnancy have been attracting attention.

In this study, we aimed to develop a program to support fathers during pregnancy in Japan. In doing so, we reviewed the research on fathers during pregnancy in Japan to clarify the characteristics of professional support for fathers during pregnancy.

\section{Methods}

\subsection{Search Method}

To examine the domestic literature, a search was conducted on January 31, 2021, using the Central Journal of Medicine ver. 5.0. The keywords used were "pregnancy \& father" and "pregnancy \& husband," wherein 110 original articles and nursing literature were retrieved. Among them, except for conference proceedings, 100 articles had abstracts. The contents of the abstracts were then checked, wherein 30 articles that had descriptions of pregnancy and fatherhood were obtained from the literature. We read the available literature, excluding review literature and literature on biological fathers of pregnant women, and selected 27 articles for this study. (List of target documents)

\subsection{Ethical Considerations}

Only published literature was used.

\section{Results}

For the past 10 years, 12 articles were published from 2010 to 2015, while 15 were published from 2016 to 2020 . The subjects of these studies were as follows: municipalities in 1 case, pregnant women only in 2 cases, couples in 8 cases, and fathers only in 16 cases. Self-administered questionnaires were the most common research method used in 18 cases, semi-structured interviews were used in 6 cases, focus group interviews were used in 1 case, and a mixed method research was used in 1 case. In the mixed research method, a program to promote fathers' participation in childcare was developed and implemented, and for evaluation, questionnaires and recorded data from social gatherings were analyzed and evaluated using observational information.

The literature was carefully read and classified into three major categories according to the purpose and target of the study: (1) evaluation of support programs during pregnancy, (2) studies with pregnant women and couples, and (3) studies with fathers. Among them, the content of the results on fathers was delimited by meaningful sentences as a code. The results were categorized into subcategories and categories according to similarity.

The categories are expressed with single quotation marks ("), whereas the subcategories are expressed with double quotation marks ("')).

\subsection{Studies Examining Support Programs for Parents}

In the study on the actual conditions of pregnancy in municipalities across Japan (Reference No. 2), the following category and subcategory were extracted: "lecture/exercise format and contents of implementation," "interaction between fathers and other participants," and 'examination of program implementation methods.' In the study on the actual condition of pregnancy in municipalities across Japan (Ref. No. 2), the status of implementation of prenatal education in municipalities across Japan was ascertained; 69.4\% of municipalities conducted either both or one of the following: parents' classes and antenatal classes. Of those who reported their pregnancy, $17.9 \%$ of pregnant women and $12.3 \%$ of their partners attended these classes. In the parents' class, the role of the father was most frequently implemented in the lecture format. The most common exercises were carrying the baby and wearing a jacket for the father to experience pregnancy.

The results of the evaluation of the program were as follows: "Fathers' participation in childcare and household 
chores increased" and "Fathers' awareness and role as fathers improved." In the study that examined the contents of support programs during pregnancy (Ref. Nos. 7, 12, 14, and 18), support programs were implemented in the private sector, such as clinics and child-rearing plazas. In the development of programs to promote fathers' participation in child-rearing, the usefulness of programs in which fathers and mothers share time and space from the time of pregnancy was suggested. As the effects of the program, "fathers' participation in child-rearing increased," and "fathers' housework behavior increased." In addition, a study on the evaluation of the clinic's parent education class (Ref. No. 26) identified the following reasons for attending the class: to deepen knowledge about the baby, prepare for parenthood, and learn together as a couple rather than alone.

\subsection{Research on Pregnant Women and Couples}

"Deepening of the relationship with the husband who is growing into a father," "Adjustment of the couple's relationship and domestic roles," and 'Expectations from pregnant women to the husband's role as a father' were the themes extracted. In the studies examining pregnant women (Ref. Nos. 1 and 17), the primary aim was to understand the current situation in terms of comfort experienced by pregnant women and the support they get in the second half of pregnancy and the characteristics of comfort during pregnancy among working pregnant women. Whether it is their first time being pregnant, menstruating women or they are working or not, deepened relationship with their husbands, who were growing into fathers, was noted to be related to the comfort of pregnant women. They also commented that they wished they had been able to discuss childcare from the time of pregnancy.

"Fathers' anxiety and confusion about pregnancy and childbirth" and "construction of family relationships and formation of father roles before and after childbirth" were also extracted. The results of the study were as follows: Studies examining couples (Ref. Nos. 3, 9, and 22) had been conducted to understand the readiness of fathers over first time mothers and investigate the relationship between adaptation to pregnancy and personal background. It was revealed that as fathers, they were searching for their own role in the family and were confused by unknown phenomena that they could not experience. The results showed that the partner's marital status with the pregnant woman at the time of pregnancy and the positive feelings of himself and his parents were adaptable to the wife's acceptance of pregnancy and becoming a father.

In a study in which questionnaires were administered to wives during pregnancy and after childbirth, physical and mental health were found to be lower among fathers with multiple children than among fathers of only one child. In addition, physical functioning and child-rearing anxiety were related to the level of physical and mental health of husbands.

\subsection{Content Targeted at Fathers}

"Knowledge and experience of child-rearing skills during pregnancy is necessary," "Increased satisfaction through experience of improved child-rearing skills," and "Satisfaction through experience of improved child-rearing skills from pregnancy' were extracted. In a study that examined husbands whose wives were pregnant (Ref. Nos. 4, 8, 10, and 25), it was found that most men become aware of fatherhood when they learned of their wives' pregnancies, which is a result of the events they experienced working on themselves from the pregnancy period. The awareness of fatherhood was strengthened by accompanying their wives to antenatal checkups and hearing the results, seeing images of the fetus, and touching the abdomen. In the case of husbands with pregnant wives, the higher their proximity score was, the more attached them were to their children. The higher the approach score, the more attached the father is to the child. The importance of the father's experience of interacting with the child, such as holding the baby, was pointed out because the approach score was higher for those who had had contact with the child. In a study on the experiences and needs of husbands who participated in the parents' class, the results showed that the husbands were satisfied with the technical guidance in the parents' class after trying to raise their children.

"Sharing of emotions between husband and wife is important," "Support for wife and interest in the child connected to the marital relationship," and "Association between marital intimacy from the pregnancy stage and the relationship to the mother and child' were extracted. In a study examining husbands whose wives were pregnant (Ref. Nos. 5 and 6), the higher the marital affection score, the more supportive the husbands were of their wives and the more interested they were in their children. In addition, the results of self-evaluation showed that those who selected as their ideal father image a husband who is good to their children and wife are more capable of practicing husbandly behavior toward pregnant women than those who did not.

'Role adjustment between the workplace and home from the pregnancy period' was extracted, including "Need to gain understanding from the workplace" and "Think about work-family balance." 
In studies examining fathers' experiences when their wives were pregnant (Ref. Nos. 19, 20, 21, and 27), the results showed that fathers made efforts to gain understanding of their workplaces, such as devising their own work arrangements. The results also showed that fathers were aware of the fatherhood roles that those around them wanted them to take on, such as financial responsibility and responsibility for stable family relationships, and recognized the need for them to take on these roles. In a study that investigated what kind of information fathers wanted to know from pregnancy to delivery and after childbirth, it was determined that they are mostly curious on the growth of the fetus, nutrition during pregnancy, and abnormalities during pregnancy and how to cope with them; meanwhile, after childbirth, they wanted to know about emergency responses, especially to dealing with situations such as the baby's illness and social systems.

"I can only imagine the mother and child changing day by day," "Anxiety and worry due to not knowing," and 'Vague imagination and anxiety during pregnancy' were extracted. In a study that examined fathers' thoughts and feelings when their wives were pregnant (Ref. Nos. 11, 13, 15, 16, and 23), fathers who had no knowledge of child-rearing from the time they found out they were pregnant felt anxious and confused and sought ways to help while feeling the burden of balancing work and family. They eventually came to feel that they had no choice and that they had to be patient for now. In addition, from the experiences of husbands who participated in the parents' class, the results of a lack of image of pregnancy and childbirth and an uncomfortable space for men were extracted. The most common concern of husbands during pregnancy throughout the entire period was the course of the pregnancy. Other concerns were morning sickness and, in the second trimester, ensuring that the partner had enough sleep and sharing household chores. In terms of what husbands wanted to know, the most common topics were how to cope with abnormalities in pregnancy, what they could do to help, and how to raise children. Research on psychological changes in husbands during pregnancy revealed anxiety due to a lack of knowledge, such as not knowing what to expect during their first pregnancy and not knowing how to support their wives. Only a few studies attempted to understand the mental state of fathers, such as the actual state of husband's depression during pregnancy and related factors, and the level of husband's physical and mental health and related factors.

Table 1. Studies examining the support programs for parents

\begin{tabular}{ll}
\hline Category & Subcategory \\
\hline Examination of how the program is implemented & Lecture/exercise format and content \\
& Interaction between fathers and other participants \\
& Timing and frequency of implementation \\
\hline Effectiveness and evaluation of program implementation & $\begin{array}{l}\text { Increase in fathers' participation in child-rearing and } \\
\text { housework behavior } \\
\text { Increase in caring behavior toward wives } \\
\text { Increased awareness of fatherhood and role as a father } \\
\text { Increased interaction with others }\end{array}$ \\
\hline
\end{tabular}


Table 2. Studies with pregnant women and couples

\begin{tabular}{ll}
\hline Category & Subcategory \\
\hline $\begin{array}{l}\text { Expectation of fatherhood role from pregnant women to } \\
\text { their husbands }\end{array}$ & $\begin{array}{l}\text { Deepening relationship with husband as he grows into a } \\
\text { father } \\
\text { Marital relationship and role adjustment in the home }\end{array}$ \\
\hline Fathers' anxiety and confusion from pregnancy & $\begin{array}{l}\text { Fathers' confusion and anxiety about pregnancy and } \\
\text { childbirth }\end{array}$ \\
$\begin{array}{l}\text { Building family relationships and forming father roles } \\
\text { before and after childbirth }\end{array}$ & $\begin{array}{l}\text { Searching for the father's role } \\
\text { Mental health during pregnancy and postpartum }\end{array}$ \\
$\begin{array}{l}\text { Husband's anxiety about child-rearing and physical } \\
\text { functioning affecting physical and mental health } \\
\text { Physical and mental health is affected more after the } \\
\text { second child than after the first child }\end{array}$ \\
\hline
\end{tabular}

Table 3. Studies on fathers

\begin{tabular}{|c|c|}
\hline Category & Subcategories \\
\hline \multirow[t]{5}{*}{$\begin{array}{l}\text { Satisfaction from the experience of parenting skills from } \\
\text { pregnancy }\end{array}$} & $\begin{array}{l}\text { Need for knowledge and experience of parenting skills } \\
\text { from the pregnancy period }\end{array}$ \\
\hline & $\begin{array}{l}\text { Need to experience contact with the child from the } \\
\text { pregnancy period }\end{array}$ \\
\hline & $\begin{array}{l}\text { Increased satisfaction through experience of improved } \\
\text { parenting skills }\end{array}$ \\
\hline & $\begin{array}{l}\text { Satisfied with guidance on child-rearing skills at } \\
\text { parent-teacher classes }\end{array}$ \\
\hline & $\begin{array}{l}\text { Self-awareness through experience of touching and } \\
\text { listening to the child during antenatal checkups }\end{array}$ \\
\hline \multirow[t]{4}{*}{$\begin{array}{l}\text { Relationship between marital intimacy and relationship } \\
\text { to mother and child from pregnancy }\end{array}$} & $\begin{array}{l}\text { Emotional sharing between husband and wife is } \\
\text { important }\end{array}$ \\
\hline & $\begin{array}{l}\text { An affectionate relationship between the husband and } \\
\text { wife influences support for the wife and interest in the } \\
\text { child }\end{array}$ \\
\hline & $\begin{array}{l}\text { Fathers who decide to be present as a couple have a high } \\
\text { level of intimacy }\end{array}$ \\
\hline & $\begin{array}{l}\text { Marital intimacy is influenced by the husband's } \\
\text { relationship with the child }\end{array}$ \\
\hline \multirow[t]{3}{*}{$\begin{array}{l}\text { Role adjustment at work and at home from the period of } \\
\text { pregnancy }\end{array}$} & Need to gain understanding from the workplace \\
\hline & Consider the balance between work and family roles \\
\hline & $\begin{array}{l}\text { Need to know what to do in case of emergency and } \\
\text { social systems }\end{array}$ \\
\hline \multirow[t]{2}{*}{ Vaguely imaginative and anxious during pregnancy } & $\begin{array}{l}\text { I can only imagine how the mother and child are } \\
\text { changing day by day }\end{array}$ \\
\hline & Anxiety and worry due to not knowing \\
\hline
\end{tabular}




\section{Discussion}

During the same period that this present literature was published, a literature search on "pregnancy \& mothers" and "pregnancy \& wives" instead of fathers, the theme of this study, yielded a total of 354 studies. Although it is not a simple comparison, it can be noted that the number of studies on mothers is approximately three times larger than that on fathers, and the number of studies on fathers is smaller than that on mothers during pregnancy. This may be due to the reality that mothers are primarily responsible for childcare and that it is easier to obtain data from mothers. There is a tendency for the role of fathers to be expected from the perspective of mothers or those involved. In the future, research should be conducted from the perspective of fathers.

\subsection{Research on Fathers in Pregnancy}

In this study, we were able to understand the actual situation of group support provided by local governments, clinics, and private organizations. At the parents' and mothers' classes, lectures and exercises have been conducted focusing on knowledge and skills related to child-rearing. However, the number of fathers who attended the classes was limited to a few percent of the total number of eligible fathers. Pregnant parents who are about to give birth for the first time are less reluctant to receive education and assistance. Pregnancy can be considered a sensitive period for parenting learning. It has been pointed out that providing enough information and learning opportunities during this sensitive period is effective in prevention (Horiguchi, 2005). In the parents' class, fathers had no image of pregnancy and childbirth, and as men, they felt uncomfortable in this space. It is necessary to consider the content of the classes so that not only the mothers but also the fathers can participate and be satisfied.

The level of physical and mental health of husbands has been noted to be related to their physical health and child-rearing anxiety. Fathers, unlike mothers, do not undergo physiological changes during pregnancy. Thus, during pregnancy, they often feel anxious and confused about such unknown phenomena that they cannot experience, thus leaving them searching for their roles (Decker, 2015). Before childbirth, it is thus necessary to gain knowledge about child-rearing and be aware of how a couple should raise a child. In Japan, research on postpartum depression has been conducted since the father's pregnancy (Takehara, 2020). Parental depression during pregnancy can be a risk factor for attachment to the child. Therefore, it is necessary to obtain knowledge, imagine, and overcome anxiety and confusion during this pregnancy period and before childbirth. To address the mental health issues of the family during pregnancy and childbirth, it is necessary to focus on and support the mental health of the father from the beginning of pregnancy.

\subsection{Needs for Father Support}

Fathers' own decision-making and experiential learning were found to be significant. The fathers felt satisfied with the exercises and technical instruction in the class, suggesting the importance of experience. A class format that incorporates fathers' own decision-making and hands-on learning is effective. There was also a clear need to deepen knowledge about babies (Tokutake, 2017). Until now, mothers have been the main source of knowledge as regards childcare methods, the course of pregnancy, and social resources. It is also necessary to consider how to communicate the information that fathers want to know.

Mothers pointed out that the deepening of the relationship with the husband growing into a father, the affectionate relationship between the couple, and gaining knowledge about child-rearing and having a sense of child-rearing as a couple before childbirth may change the father's thoughts in a positive way (Inoue, 2017). The number of nuclear families is increasing, and low communication between couples is also being pointed out. It has been indicated that marital conflicts may be heightened because of the different cultures of fathers and mothers when they are about to become parents (Inuduka et al., 2009). Since there was a need for two people to learn together rather than one, it is significant for both spouses to discuss and share their roles in preparing for parenthood and imagining life from pregnancy to postpartum. It is even more significant for couples to learn, share, and communicate together.

\subsection{Issues in Practice Focusing on Fathers in the Future}

The results showed that the deeper the relationship between mothers and their husbands growing into fathers during pregnancy and the higher the marital affection score, the higher the quality of fathers' involvement with their partners and fathers' involvement with their children. It is necessary to share spend time with one's partner, share feelings, and deepen the marital relationship.

There are few opportunities for fathers to receive support during pregnancy. The issue is how to create opportunities and methods of support for parents. The role of fathers has been changing in recent years, and with the nuclear family and declining birth rate, fathers are expected to take on more of the household and childcare 
roles. However, men's working hours are still long, and it has been reported that there is a large difference in the amount of time spent on housework and childcare compared with those of women (Cabinet Office, 2020). How should work and housework/childcare be balanced? Not only the awareness of fathers but also a working style that enables them to secure time for family involvement must be realized.

\section{Conclusion}

This study has reviewed the domestic literature and has further summarized the results of studies examining fathers during pregnancy. As per our findings, it was determined that fathers seldom participate in the implementation of support programs during pregnancy. Fathers' anxiety and confusion were noted all throughout the pregnancy period. Research on fathers' mental health has just begun. To increase fathers' satisfaction, it is thus necessary to create a space where fathers themselves feel comfortable in understanding their needs. In the future, the challenge will be to develop support programs that go beyond lectures and exercises to deepen the relationship with their partners. It is hoped that this will lead to the acceptance of fatherhood and adaptation to life in the perinatal period.

This study reviewed only Japanese studies, but not studies from outside Japan. The reason for this is that there are cultural differences between Japan and other countries in terms of child-rearing systems, fatherhood roles, etc., and therefore, they should not be treated in the same way. However, we believe that there are similarities in the situation regarding child-rearing and the needs of fathers in other countries as well. In the future, it is necessary to keep abreast of research trends in other countries to develop better support programs for fathers.

This study was supported by JSPS KAKENHI Grant Number JP18K11853. The authors declare no conflicts of interest associated with this manuscript.

List of target documents

\begin{tabular}{|c|c|c|c|c|}
\hline No & Purpose of the study & Year & Methodology & Subject \\
\hline 1 & $\begin{array}{l}\text { To clarify the status of subjective comfort of } \\
\text { pregnant women in the second half of pregnancy, } \\
\text { comparing first-time pregnant women and } \\
\text { trans-pregnant women }\end{array}$ & 2020 & $\begin{array}{l}\text { Self-administered } \\
\text { questionnaire } \\
\text { survey }\end{array}$ & $\begin{array}{l}87 \text { pregnant women in the last } \\
\text { trimester of pregnancy }\end{array}$ \\
\hline 2 & $\begin{array}{l}\text { To understand the actual status of prenatal education } \\
\text { in municipalities nationwide }\end{array}$ & 2020 & $\begin{array}{l}\text { Self-administered } \\
\text { questionnaire } \\
\text { with no names }\end{array}$ & $\begin{array}{l}1,914 \text { cities, towns, and villages in } \\
\text { Japan }\end{array}$ \\
\hline 3 & $\begin{array}{l}\text { To clarify the state of readiness of husbands who } \\
\text { will become fathers for the first time over their } \\
\text { wives' childbirth }\end{array}$ & 2020 & $\begin{array}{l}\text { Semi-constructive } \\
\text { interview }\end{array}$ & $\begin{array}{l}5 \text { couples of first-time mothers after } \\
32 \text { weeks of pregnancy who } \\
\text { participated in the parent education } \\
\text { class }\end{array}$ \\
\hline 4 & $\begin{array}{l}\text { To understand the ideal image of fatherhood and its } \\
\text { content for men who will soon become fathers and } \\
\text { examine the relationship between this image and the } \\
\text { husband's role behavior toward the pregnant woman }\end{array}$ & 2020 & $\begin{array}{l}\text { Open-ended } \\
\text { self-administered } \\
\text { questionnaire }\end{array}$ & $\begin{array}{l}\text { Fathers of first children whose } \\
\text { wives/partners are } 36 \text { weeks or more } \\
\text { pregnant }\end{array}$ \\
\hline 5 & $\begin{array}{l}\text { To focus on the wife's pregnancy period and clarify } \\
\text { the husband's feelings and involvement at that time }\end{array}$ & 2019 & $\begin{array}{l}\text { Semi-structured } \\
\text { interview }\end{array}$ & $\begin{array}{l}5 \text { male public health nurses working } \\
\text { in the municipality }\end{array}$ \\
\hline 6 & $\begin{array}{l}\text { To clarify the differences in husbands' support } \\
\text { behaviors for their wives during pregnancy and their } \\
\text { interest in the fetus between midwifery clinics and } \\
\text { hospital checkups, and the factors related to these } \\
\text { differences. }\end{array}$ & 2018 & $\begin{array}{l}\text { Self-administered } \\
\text { questionnaire }\end{array}$ & $\begin{array}{l}328 \text { husbands of postpartum mothers } \\
\text { who gave birth at term, vaginally, or } \\
\text { within } 1 \text { week after delivery }\end{array}$ \\
\hline 7 & $\begin{array}{l}\text { To study how to plan and implement a regular and } \\
\text { continuous child-rearing support program from the } \\
\text { pregnancy period to the postpartum period }\end{array}$ & 2018 & $\begin{array}{l}\text { Questionnaires } \\
\text { and audio } \\
\text { recordings }\end{array}$ & Mothers and fathers \\
\hline
\end{tabular}


To clarify experiences before, during, and

8 immediately after participation in parent education classes, as well as thoughts and needs after childbirth

To clarify the level of physical and mental health of husbands (fathers) from the time of their wives' pregnancy through the postpartum period, and the factors related to this.

To clarify the events that triggered husbands'

10 awareness of fatherhood during their wives' pregnancy, delivery, and postpartum period

To clarify the emotions of husbands with pregnant

11 wives toward their children and examine support for fathers

\begin{tabular}{|c|c|c|}
\hline 12 & $\begin{array}{l}\text { To explore a practical model for supporting } \\
\text { child-rearing based on findings from the } \\
\text { development and examination of programs to } \\
\text { promote fathers' participation in child-rearing }\end{array}$ & 2016 \\
\hline 13 & $\begin{array}{l}\text { To clarify changes in fathers' feelings toward } \\
\text { child-rearing }\end{array}$ & 2016 \\
\hline 14 & $\begin{array}{l}\text { To clarify the relationship between fathers' and } \\
\text { mothers' feelings and involvement with their } \\
\text { children experienced during pregnancy and their } \\
\text { subjective sense of well-being }\end{array}$ & 2016 \\
\hline 15 & $\begin{array}{l}\text { To clarify the reliability and validity of a scale to } \\
\text { measure the degree to which husbands practice their } \\
\text { role behavior toward pregnant women }\end{array}$ & 2016 \\
\hline
\end{tabular}

\section{To clarify experiences before, during, and \\ 17 immediately after participation in parent education classes, as well as thoughts and needs after childbirth}

16 factors related to depression during the pregnancy period of the wife who is progressing well

To clarify the level of physical and mental health of husbands (fathers) from the time of their wives' pregnancy through the postpartum period and the factors related to this

2015

Self-administered

questionnaire with no names

\section{Self-administered 73 husbands of pregnant women}

questionnaire

Self-administered

2015

questionnaire

with no name

Self-administered questionnaire

2014

To clarify the events that triggered husbands'

19 awareness of fatherhood during their wives' pregnancy, delivery, and postpartum period

To clarify the emotions of husbands with pregnant

20 wives toward their children and examine support for fathers

To explore a practical model for supporting

21 child-rearing based on findings from the development and examination of programs to promote fathers' participation in child-rearing child-rearing ages of 0 and 3 years clinics 1-month checkup

2014 self-administered their wives as valid responses questionnaire

Self-administered Husband and wife

2014 questionnaire deliver

2014 questionnaire
Semi-structured

2 husbands who participated in the parent education class

42 couples who reported their pregnancy to the city health center

Couples who attended the class together or husbands who witnessed the delivery
Self-administered Husbands with a pregnant wife

Focus group $\quad 5$ fathers who participated in a child-raising circle

Self-administered 774 fathers and mothers who use day questionnaire care centers

urvey

542 fathers with children between the

Pregnant women attending outpatient

All first-time mothers and their partners who attended a parent education class at an obstetrics and gynecology clinic and underwent a

Anonymous Husbands who attended the birth of

Self-administered 80 husbands of pregnant women who 2014 questionnaire received antenatal checkups at a general hospital and are scheduled to

Self-administered Couples who became parents for the 
To clarify the relationship between fathers' and mothers' feelings and involvement with their children experienced during pregnancy and their subjective sense of well-being

To clarify the reliability and validity of a scale to

24 measure the degree to which husbands practice their role behavior toward pregnant women

\begin{tabular}{llll}
\hline 25 & $\begin{array}{l}\text { To clarify the reality of husband's depression and the } \\
\text { factors related to depression during the pregnancy } \\
\text { period of the wife who is progressing well }\end{array}$ & $\begin{array}{l}\text { Semi-constructive } \\
\text { interview method }\end{array}$ & $\begin{array}{l}4 \text { husbands expecting their first child } \\
\text { for the first time }\end{array}$ \\
\hline 26 & $\begin{array}{l}\text { To clarify experiences before, during, and } \\
\text { immediately after participation in parent education } \\
\text { classes, as well as thoughts and needs after childbirth }\end{array}$ & $\begin{array}{l}\text { Self-administered } \\
\text { questionnaire }\end{array}$ & 65 couples having their first child \\
\hline 27 & $\begin{array}{l}\text { To identify the experiences of first-time parents that } \\
\text { led them to consider postpartum fatherhood behavior }\end{array}$ & 2010 & $\begin{array}{l}\text { Semi-constructive } \\
\text { interview method }\end{array}$ \\
\hline
\end{tabular}

Fathers

Support programs

Pregnant women and couples

\section{References}

Adachi, Y. (2020). A survey of efforts to encourage fathers to participate in parenting in the setting of municipal prenatal education. Setsunan University Nursing Research, 8(1), 55-62.

Decker, K. (2015). Review of literature on fathers' recognition. Journal of the Japanese Association of Rural Medicine, 64(4), 718-724. https://doi.org/10.2185/jjrm.64.718

Gender equality bureau, cabinet office. (2020). 2020 years version of the white book of male and female co-participants. Retrieved from www.gender.go.jp/about_danjo/whitepaper/r02/gaiyou/pdf/r02_gaiyou.pdf

Horiguchi, M. (2017). Parenting education during prenatal period: A program with gender and developmental perspectives in the U.S. F-GENS Journal, No4 September 2005, 13-22.

Inoue, C., \& Nagashima, R. (2017). Effects of prenatal class on the feelings toward babies and childrearing motivation of expectant fathers: communication with other couples with their babies in a prenatal class. Bulletin of the University of Shimane Izumo Campus, 12, 1-10.

Kojim, Y. (2014). Effects of a support program on the psychological well-being of first-time mothers who show difficulties parenting. Sizawa M. Pediatrics and Health Research, 73(2), 347-353.

Labor and Welfare. (2021). Syakaihosyousingikaizidougyakutaitouhogozireinokentoukai. The 17's Analysis Reports by Death Cases of Child Abuse and Neglect. Ministry of Health. Retrieved October 2021, from https://www.mhlw.go.jp/content/11900000/000822359.pdf

Maternal and Child Health Division, Child and Family Bureau. (2021). Recent trends in maternal and child health administration. Ministry of Health, Labor and Welfare. Retrieved October 2021, from https://www.mhlw.go.jp/content/10800000/000765911.pdf

Nakayama, A. (2012). Successes and challenges of parental support programs: A project for symbiotic community development. Comprehensive Regional Studies, 19(1), 95-107.

Nonoyama, H. (2010). How to support parent learning. Hyogo earthquake memorial 21st-century research institute, $1-52$.

Sato, T. (2006). A guide to running a parents class at a municipal health center. Report on the 2006 Ministry of Health, Labor and Welfare Scientific Research Project on Children and Families, 1, 31-156.

Takehara, K., Suto, M., \& Kato, T. (2020). Parental psychological distress in the postnatal period in Japan: a population based analysis of a national cross sectional survey. Scientific Reports, 10(1), 13770. https://doi.org/10.1038/s41598-020-70727-2 
Tokutake, C., Haga, A., et al.. (2017). Influence of course on the first time becoming a parent on the couples thoughts and behaviors: from pregnancy to childbirth. Nagano Journal of Maternal and Child Health, 19, $13-22$.

Watanabe, K., Ishii, K., et al.. (2019). Antenatal parenting class aiming to enhance empathy between partners for prevention of postpartum depression: a traial at a hospital to assess attendants. empathy level and mental health status and to verify their ecalution of the session. Journal of the Japanese Health and Human Ecology, 85(2), 80-89. https://doi.org/10.3861/kenko.85.2_80

\section{Copyrights}

Copyright for this article is retained by the author(s), with first publication rights granted to the journal.

This is an open-access article distributed under the terms and conditions of the Creative Commons Attribution license (http://creativecommons.org/licenses/by/4.0/). 